\section{Stability of fetal hemoglobin levels in patients receiving metformin therapy}

Recently, in vitro studies using progenitor-derived erythroid cells from normal individuals or sickle cell disease (SCD) patients, have identified metformin, an oral hypoglycemic drug, as a promising agent to increase fetal hemoglobin $(\mathrm{HbF})$ levels. ${ }^{1-3}$ The mechanisms through which metformin increases $\mathrm{HbF}$ involve Forkhead box $\mathrm{O}$ transcription factor-3 (FOXO3) and adenosine monophosphate (AMP)-activated protein kinase (AMPK) pathways, which are key in controlling $\mathrm{HbF}$ regulation. ${ }^{3}$ In addition, these in vitro experiments have demonstrated that induction of $\mathrm{HbF}$ with metformin is somehow superior to hydroxyurea, and the combination of the two agents show additive effects. ${ }^{2}$ In light of these findings, a pilot study of metformin in patients with hemoglobinopathies is presently enrolling (clinicaltrials.gov Identifier: 02981329). While in vitro studies have clearly demonstrated that metformin possesses the qualities necessary to increase $\mathrm{HbF}$ levels, data on its effectiveness in vivo are still lacking. Due to the widespread use of metformin to treat patients with diabetes and other medical conditions, a longitudinal exploratory study of patients taking metformin for long periods of time was conducted to ascertain whether the clinical use of metformin at a standard dose had any ancillary effect on $\mathrm{HbF}$ levels. To this end, a retrospective study was conducted at the Sultan Qaboos University Hospital (SQUH). Data were collected from both patients attending the outpatient clinic and the pharmacy records at SQUH over a period of nine years. The study included patients aged above 15 years and who had taken metformin for at least six months and had at least three $\mathrm{HbF}$ assessments at threemonth intervals. The medication history of the enrolled patients was carefully evaluated. Patients with a previous history of severe medical illnesses, such as malignancies, severe infections, liver cirrhosis, heart failure and renal failure, as well as pregnant women and patients taking insulin or sulfonylurea were excluded. For each patient, the socio-demographic characteristics, clinical and laboratory data and treatment details were extracted. Enrolled patients were followed up starting from the first $\mathrm{HbF}$ reading prior to metformin therapy until three months after the last $\mathrm{HbF}$ assessment. The pharmacy refill adherence to metformin was measured using electronic pharmacy records and was defined as ([pills dispensed/ pills prescribed per day]/days between refills] $\times 100$ ), as previously reported by Grossberg et al. ${ }^{4} \mathrm{HbF}$ levels were determined by cation-exchange high-performance liquid chromatography (HPLC; Bio-Rad VARIANT, CA, USA), and the analyzer Integra 400 (Roche Diagnostics, IN, USA) was used to quantify glycated hemoglobin A1c (HbA1c). ${ }^{5}$ The study was approved by the Institutional Research Ethic Committee of the SQU, Sultanate of Oman. One-way ANOVA and non-parametric statistics were used to evaluate the differences, which were set at a $P$-value of $<0.05$ (GraphPad PRISM 5.0 software, CA, USA). Of all the participants screened, seven patients met the inclusion and exclusion criteria. Table 1 summarizes the baseline characteristics of qualified patients. Overall, $57 \%$ were male with a median age of 35 years. Metformin therapy was given at a median dose of $1500 \mathrm{mg} /$ day with a range from 1000 to $2000 \mathrm{mg} /$ day. The median treatment length with metformin was 71 months. Three patients (34\%) had polycystic ovarian syndrome (PCOS), while four patients (57\%) had type 2 diabetes mellitus (T2DM). Of note, none of the patients showed abnormal hemoglobins, received transfusions or developed renal impairments during the study period. In addition to metformin, $61 \%$ of patients were taking folic acid and $38 \%$ mefenamic acid. Statins were given to $31 \%$ of the T2DM patients. In all the patients studied, $\mathrm{HbF}$ levels did not significantly change over time (Figure 1). Significantly, $\mathrm{HbF}$ measurements were not performed as part of the routine clinical care in this study population. To further explore the effect of metformin therapy on

Table 1. Major demographic and clinical characteristics of study participants.

\begin{tabular}{|c|c|c|c|c|c|c|}
\hline Case & Age (Year) & Sex & Diagnosis & $\begin{array}{l}\text { Duration } \\
\text { of metformin } \\
\text { therapy } \\
\text { (Months) }\end{array}$ & $\begin{array}{l}\text { Metformin } \\
\text { dosage } \\
\text { (mg/day) }\end{array}$ & $\begin{array}{l}\text { Hemoglobin F prior } \\
\text { to metformin therapy } \\
(\%)\end{array}$ \\
\hline 1 & 30 & $\mathrm{~F}$ & $\begin{array}{l}\text { Polycystic } \\
\text { ovarian } \\
\text { syndrome }\end{array}$ & 14 & 1500 & 0.3 \\
\hline 2 & 32 & $\mathrm{~F}$ & $\begin{array}{l}\text { Polycystic } \\
\text { ovarian } \\
\text { syndrome }\end{array}$ & 15 & 1000 & 0.7 \\
\hline 3 & 35 & $\mathrm{~F}$ & $\begin{array}{l}\text { Polycystic } \\
\text { ovarian } \\
\text { syndrome }\end{array}$ & 16 & 1500 & 0.3 \\
\hline 4 & 30 & M & Type 2 diabetes & 83 & 1500 & 0.2 \\
\hline 5 & 49 & M & Type 2 diabetes & 84 & 2000 & 1.1 \\
\hline 6 & 41 & M & Type 2 diabetes & 75 & 2000 & 1.4 \\
\hline 7 & 39 & M & Type 2 diabetes & 71 & 1500 & 0.5 \\
\hline $\begin{array}{l}\text { Mean } \pm \text { SD } \\
\text { (Range) }\end{array}$ & $\begin{array}{l}36 \pm 7 \\
(30-49)\end{array}$ & $\mathrm{NA}$ & $\mathrm{NA}$ & $\begin{array}{l}51 \pm 34 \\
(14-84)\end{array}$ & $\begin{array}{c}1571 \pm 345 \\
(1000-2000)\end{array}$ & $0.64 \pm 0.45$ \\
\hline
\end{tabular}


$\mathrm{HbF}$ levels, data were evaluated according to the time length of follow-up periods. HbF levels were grouped into three categories: prior to metformin therapy, i.e., baseline, $12 \pm 9$ months after therapy, and $24 \pm 9$ months thereafter. Compared to baseline, HbF levels did not significantly increase after $12 \pm 9$ months and $24 \pm 9$ months of therapy $(0.6 \pm 0.17 \%$ versus $0.71 \pm 0.16 \%$ and $0.72 \pm$ $0.2 \%$; $P=0.58$; respectively). Of interest, $\mathrm{HbF}$ levels remained comparable between patients taking $500 \mathrm{mg}$ three times daily and those receiving $1000 \mathrm{mg}$ twice daily $(P=0.87)$. Similarly, patients who received metformin for less than 24 months exhibited comparable $\mathrm{HbF}$ levels to patients taking metformin for more than 24 months $(P=0.42)$. Collectively, these findings suggest that metformin therapy had a limited impact on $\mathrm{HbF}$ levels in PCOS and T2DM patients. Compliance with metformin therapy ranged from $95 \%$ to $100 \%$ with a median of $100 \%$, suggesting an excellent adherence to metformin. The levels of HbA1c significantly decreased at $24 \pm 9$ months $(6.1 \pm 0.6 \%)$ compared to levels prior to metformin therapy in T2DM patients $(8.7 \pm 1.1 \%$; $P=0.045)$. As expected, the levels of HbA1c did not significantly change over time in PCOS patients (data not shown). Using the data available herein, metformin use in routine clinical practice, with the recommended current doses, has a limited effect on $\mathrm{HbF}$ levels in patients with PCOS or T2DM. It is not clear at this time how the in vitro derived data relate to the actual in vivo situation. Several explanations are possible. The first is that the current dose of metformin taken by our patients was insufficient to induce $\mathrm{HbF}$ production; however, this seems an unlikely explanation as the treatment of normal human progenitor cells with metformin caused a dose dependent increase in $\mathrm{HbF}$ levels as assessed by HPLC. ${ }^{1,2}$ In fact, experimental studies in vitro indicated that $\mathrm{HbF}$ levels increased by nearly 1 -fold after 14 days of cell culture with $50 \mu \mathrm{M}$ of metformin. ${ }^{2}$ Of interest, patients on a standard dose of metformin typically exhibit a plasma drug level of $70 \mu \mathrm{M}$. Albeit in this study the blood levels of metformin were not obtained and thus drug adherence was not directly measured, the pharmacy refill procedure could serve as a reliable and valid tool to assess adherence behavior in clinical settings. ${ }^{6}$ In the present study, all patients presented with an excellent adherence to metformin therapy by means of the pharmacy refill method. In addition, all T2DM patients exhibited a significant reduction in $\mathrm{HbA1c}$ levels from baseline, suggesting that patients are indirectly adhering to metformin therapy. Secondly the continuous use of metformin may negatively impact on the regulatory pathways of $\mathrm{HbF}$ production, leading to its inhibition. This assumption is supported by in vitro experiments showing that maximum levels of $\mathrm{HbF}$ are reached within two weeks after initiation of metformin treatment. ${ }^{2}$ Therefore, $\mathrm{HbF}$ should be assessed early, as its levels may decrease rapidly after starting metformin therapy. In this study, HbF levels were not available shortly after starting metformin therapy, and $\mathrm{HbF}$ assessments were performed randomly, generally within three months of initiating metformin. However, from a mechanistic point of view, this explanation seems unlikely because studies have revealed that metformin does not alter expression levels of known regulators of $\mathrm{HbF}$, such as the FOXO3-AMPK pathway. ${ }^{3}$ The third reason is that the effects of metformin therapy on $\mathrm{HbF}$ could be tampered with by the patient taking other drugs or herbal products simultaneously, thereby making metformin less effective. For instance, it has been shown that metformin can cause vitamin B12 deficiency leading to low hemoglobin production and anemia. Although this study could not exclude the use of non-prescribed medicines, such as vitamins and herbal products, during the study period, none of the enrolled patients was taking a drug that is known to affect the effectiveness of metformin. Lastly, $\mathrm{HbF}$ induction by metformin is less effective in
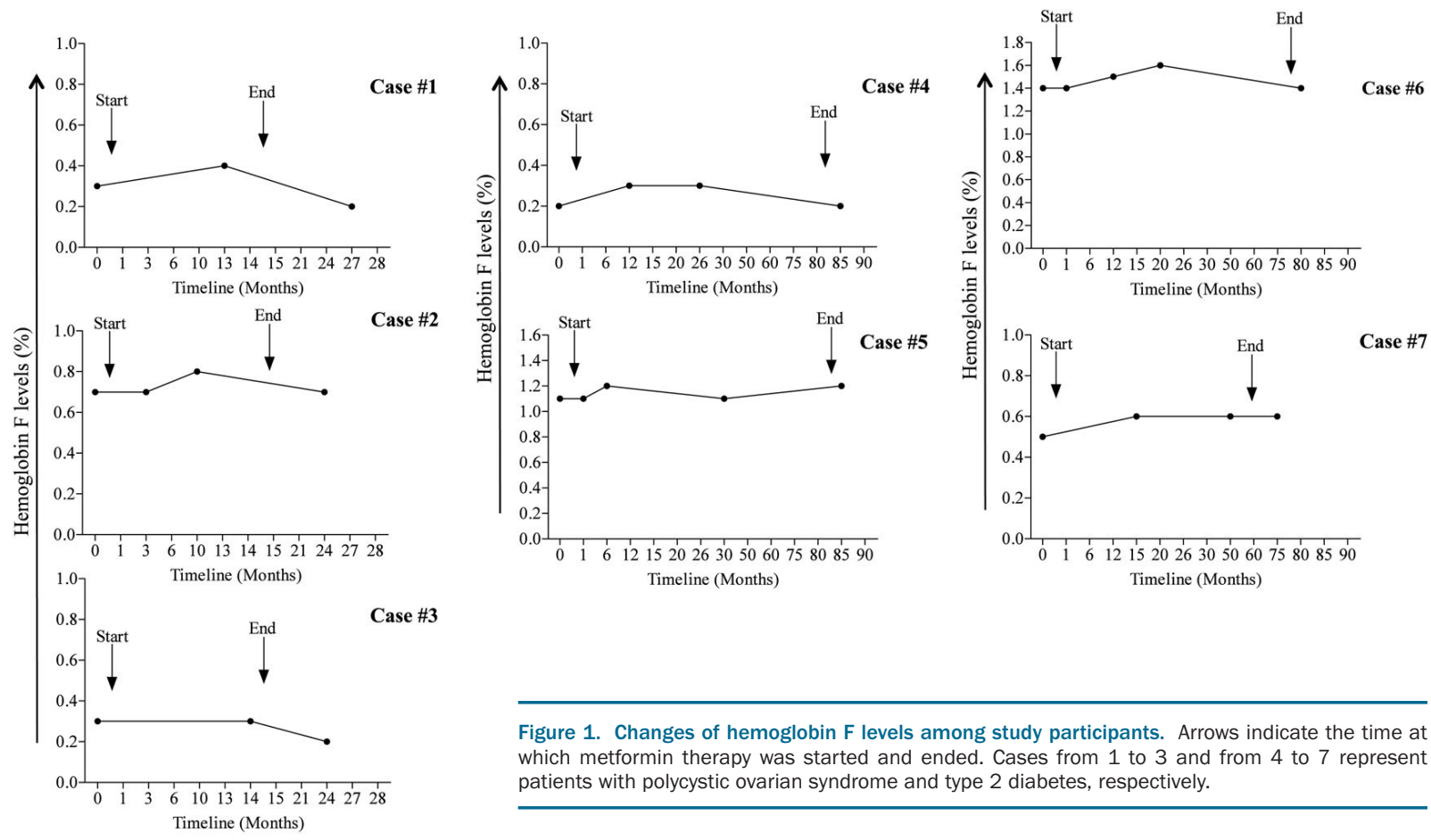

Figure 1. Changes of hemoglobin $\mathrm{F}$ levels among study participants. Arrows indicate the time at which metformin therapy was started and ended. Cases from 1 to 3 and from 4 to 7 represent patients with polycystic ovarian syndrome and type 2 diabetes, respectively. 
patients with POCS and T2D compared to patients with hemoglobinopathies, as these patients are not under erythropoietic stress. This hypothesis is reinforced by in vitro studies indicating that metformin at a dose of $100 \mu \mathrm{M}$ significantly increased $\mathrm{HbF}$ production in $80 \%$ of progenitor cells derived from SCD patients. ${ }^{3}$ Since this is the first in vivo study, it is difficult to know if the type of disease could have an impact on $\mathrm{HbF}$ production from normal bone marrow cells, in which the $\gamma$ globin genes are normally less expressed. Some potential limitations of the present study need to be emphasized. Although extracted from a large series of individuals taking metformin therapy for a variety of medical conditions, case numbers were still limited. Nevertheless, it should be noticed that this was a retrospective study over a period of nine years. Next, all data sources and diagnoses were based on physician reporting, so caution should be taken when generalizing the findings observed beyond this population. Also, the variability in the timing of $\mathrm{HbF}$ assessments could be seen as a limitation, but outcomes were compared within each individual, thereby minimizing this effect. Finally, though probably marginal as other adherence methods were used, one cannot underestimate the non-determination of plasma metformin levels in the study population; unfortunately, no data on this parameter was available. In conclusion, this is the first human study with preliminary results showing that longterm metformin therapy alone seems to be insufficient to increase $\mathrm{HbF}$ levels. Further prospective studies over prolonged treatment periods are needed to establish the relative contribution of metformin in increasing $\mathrm{HbF}$ levels in vivo, before considering its clinical usefulness as a booster of $\mathrm{HbF}$ in patients with hemoglobinopathies.

Mohamed-Rachid Boulassel, ${ }^{1,2}$ Abdal-Aziz Issa El-Hussain, ${ }^{1}$ Moataz Mohamed Hassan, ${ }^{3}$ Mohamed-Lamine Toumi, Sameha Merzoug, ${ }^{4}$ Zahra Al-Qarni, ${ }^{1}$ Hammad Khan, ${ }^{2}$ Zied Gaifer,' Khalil Al-Farsi, ${ }^{2}$ Murtadha Al-Khabori, Mohamed Al Huneini and Salam Al-Kindi

'Department of Allied Health Sciences, College of Medicine and Health Sciences, Sultan Qaboos University, Sultanate of Oman,
'Department of Haematology, Sultan Qaboos University Hospital, College of Medicine and Health Sciences, Sultanate of Oman; ${ }^{3}$ Department of Pharmacy, Sultan Qaboos University Hospital, Sultanate of Oman; ${ }^{4}$ Department of Biology, University of Chadli Bendjedid, El-Tarf, Algeria and 'Department of Medicine, Sultan Qaboos University Hospital, College of Medicine and Health Sciences, Sultanate of Oman

Acknowledgments: we are thankful to all participants and also to the Hospital Information System staff of the SQUH for providing technical assistance.

Funding: this work was supported in part by grants from the Oman Research Council (\# ORG/HSS/ 13/002) and the Sultan Qaboos

University (\#IG/MED/HAEM/14/01).

Correspondence:boulassel@squ.edu.om doi:10.3324/haematol.2018.190967

Information on authorship, contributions, and financial \& other disclosures was provided by the authors and is available with the online version of this article at www. haematologica.org.

\section{References}

1. Zhang Y, Crosby JR, Boerwinkle E, Pace B, Sheehan VA. Pharmacological induction of $\mathrm{FOXO} 3$ is a potential treatment for sickle cell disease. Blood. 2015;126(23):282.

2. Zhang Y, Weiss M, Sumazin P, Sheehan VA. Metformin induces FOXO3-dependent fetal hemoglobin production in primary erythroid cells. Blood. 2016;128(22):322.

3. Zhang Y, Paikari A, Sumazin P, et al. Metformin induction of fetal hemoglobin. Blood. 2017;130(Suppl1):359.

4. Grossberg R, Zhang Y, Gross R. A time-to-prescription-refill measure of antiretroviral adherence predicted changes in viral load in HIV. J Clin Epidemiol. 2004;57(10):1107-1110.

5. Boulassel MR, Al-Farsi R, Al-Hashmi S, Al-Riyami H, Khan H, AlKindi S. Accuracy of platelet counting by optical and impedance methods in patients with thrombocytopaenia. Sultan Qaboos Univ Med J. 2015;15(4):e463-468

6. Lam WY, Fresco P. Medication adherence measures: an overview. Biomed Res Int. 2015;2015:217047.

7. Aroda VR, Edelstein SL, Goldberg RB, et al. Diabetes Prevention Program Research Group. Long-term metformin use and vitamin B12 deficiency in the Diabetes Prevention Program Outcomes Study. J Clin Endocrinol Metab. 2016;101(4):1754-1761. 